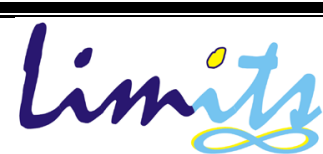

Limits: Journal of Mathematics and Its Applications

E-ISSN: 2579-8936

P-ISSN: 1829-605X

Vol. 18, No. 2, Nopember 2021, 187-202

DOI: http://dx.doi.org/10.12962/limits.v18i2.9480

\title{
Multi Criteria Decision Making menggunakan Operator Group Generalized Interval Value Pythagorean Fuzzy
}

\author{
Nurul Faqiyyatur Rokhmah ${ }^{1}$, Noor Hidayat ${ }^{1}$, Abdul Rouf Alghofari ${ }^{1}$ \\ ${ }^{1}$ Jurusan Matematika, Universitas Brawijaya, Malang, Indonesia \\ e-mail: nurulfaqiyya@gmail.com
}

Diajukan: 24 Juni 2021, Diperbaiki: 9 Agustus 2021, Diterima: 11 Agustus 2021

\begin{abstract}
Abstrak
Multi Criteria Decision Making (MCDM) adalah proses penentuan solusi terbaik dalam suatu masalah berdasarkan kriteria yang telah ditentukan. Dalam berbagai kasus, pengambil keputusan sulit untuk menyatakan pendapatnya dalam angka yang tegas. Oleh karena itu, penggunaan bilangan fuzzy dianggap lebih efisien. Salah satu bilangan fuzzy yang digunakan dalam kasus MCDM adalah Interval Value Pythagorean Fuzzy Number (IVPFN). Informasi fuzzy pada kasus MCDM dinyatakan dalam IVPFN. Akurasi informasi fuzzy dinilai oleh Group Generalized Parameter (GGP) yang dinyatakan dengan cara yang sama seperti informasi fuzzy, yaitu dengan IVPFN. Informasi fuzzy dan GGP selanjutnya diagregasi menggunakan operator Group Generalized Interval Value Pythagorean Fuzzy Weighted Average (GGIVPFWA) dan Group Generalized Interval Value Pythagorean Fuzzy Weighted Geometric (GGIVPFWG). Kedua operator tersebut bertujuan untuk menemukan alternatif terbaik yang dapat dipilih. Hasil keputusan dari operator GGIVPFWA dan GGIVPFWG selanjutnya diverifikasi menggunakan weighted similarity measure dan menunjukkan bahwa kedua operator tersebut dapat menyelesaikan masalah MCDM secara efektif dan akurat.
\end{abstract}

Kata Kunci: multi criteria decision making, interval value Pythagorean fuzzy, group generalized parameter, weighted similarity measure.

\begin{abstract}
Multi Criteria Decision Making (MCDM) is a way for figuring out the first-rate answer primarily based totally on decided criteria. In diverse cases, the decision makers discover it hard to explicit their opinion in a crisp number. So that, the use of fuzzy number is considered more efficient. One of fuzzy number commonly used in the MCDM cases is Interval Value Pythagorean Fuzzy Number (IVPFN). The fuzzy information of MCDM problem is represented by IVPFN. The fuzzy information accuracy is assessed by Group Generalized Parameter (GGP) which is represented withinside the identical technique as fuzzy information. The fuzzy information and GGP are then aggregated using Group Generalized Interval Value Pythagorean Fuzzy Weighted Average (GGIVPFWA) and Group Generalized Interval Value Pythagorean Fuzzy Weighted Geometric (GGIVPFWG) operators. The two operators aim to determine the best alternative that can be chosen. The results are then verified using weighted similarity measure and show that GGIVPFWA and GGIVPFWG can effectively and accurately solve the MCDM problem.
\end{abstract}

Keywords: multi criteria decision making, interval value Pythagorean fuzzy, group generalized parameter, weighted similarity measure.

\section{Pendahuluan}

Multi Criteria Decision Making (MCDM) merupakan proses penentuan solusi atau alternatif terbaik berdasarkan beberapa kriteria yang telah ditentukan. MCDM memberikan peringkat atau 
urutan prioritas dari yang paling menguntungkan hingga tidak menguntungkan. Dalam berbagai kasus MCDM, pengambil keputusan menyatakan pendapatnya menggunakan himpunan fuzzy yang pertama kali diperkenalkan oleh Zadeh (1965) [1]. Hal tersebut dilakukan karena pengambil keputusan sulit untuk menyatakan pendapatnya dalam angka yang tegas.

Representasi informasi fuzzy dalam kasus MCDM selanjutnya mengikuti perkembangan teori himpunan fuzzy pada [2] dan [3]. Pada tahun 2013, Yager [4] memperkenalkan teori Pythagorean Fuzzy Set (PFS). Selanjutnya, Peng dan Yang [5] memperluas konsep PFS menjadi Interval Value Pythagorean Fuzzy Set (IVPFS). IVPFS dapat merepresentasikan informasi fuzzy dengan lebih efektif dan akurat.

Akurasi informasi fuzzy ditentukan oleh Generalized Parameter (GP), suatu konsep yang diperkenalkan oleh Agarwal (2013) [6]. Namun, GP tertentu tidak dapat menilai akurasi informasi fuzzy secara akurat, sehingga diperlukan lebih banyak GP yang dihimpun dalam Group Generalized Parameter (GGP). GGP dapat menentukan akurasi informasi fuzzy dan mengurangi dampak kesalahan akibat penggunaan GP tertentu. GGP direpresentasikan dengan cara yang sama seperti informasi fuzzy.

Proses pengolahan informasi fuzzy yang dinyatakan dalam PFS menggunakan operator agregasi Pythagorean fuzzy diteliti oleh Garg pada tahun 2016 dan 2017 dalam [7] dan [8]. Selanjutnya, proses pengolahan informasi fuzzy yang dinyatakan dalam IVPFS menggunakan operator interval value Pythagorean fuzzy diteliti oleh Rahman pada tahun 2017 dan 2018 dalam [9] dan [10]. Pada tahun 2020, Feng dkk [11] meneliti tentang operator yang mengagregasi informasi fuzzy dan GGP yang dinyatakan dalam PFS.

Hasil agregasi informasi fuzzy dan GGP dengan operator agregasi Pythagorean fuzzy mungkin saja mengalami kesalahan. Oleh karena itu, konsep similarity measure digunakan untuk memverifikasi hasil dari operator agregasi Pythagorean fuzzy yang digunakan. Konsep similarity measure dari himpunan Pythagorean fuzzy diteliti oleh Zhang [12]. Sedangkan konsep similarity measure dari himpunan interval value Pythagorean fuzzy diteliti oleh Li [13].

Berdasarkan penelitian-penelitian sebelumnya, artikel ini akan membangun definisi tentang operator agregasi group generalized interval value Pythagorean fuzzy. Artikel ini juga akan memberikan kasus MCDM dengan informasi fuzzy dan GGP yang dinyatakan dalam IVPFS. Informasi tersebut selanjutnya diagregasi menggunakan operator agregasi group generalized interval value Pythagorean fuzzy. Hasil dari operator agregasi tersebut selanjutnya diverifikasi menggunakan weighted similarity measure untuk mementukan tingkat efektivitas dan akurasi dari operator agregasi yang digunakan. 


\section{Metode Penelitian}

Metode penelitian studi literatur adalah metode yang digunakan dalam penelitian ini. Sumber literatur yang digunakan berasal dari beberapa pustaka, seperti buku dan artikel ilmiah. Penelitian ini diawali dengan mempelajari teori IVPFS, GGP, dan weighted similarity measure. Kemudian membangun operator yang mengagregasi informasi fuzzy dan GGP yang dinyatakan dalam IVPFS. Selanjutnya mengaplikasikan operator agregasi dalam kasus MCDM dan memverifikasi hasil yang diperoleh menggunakan weighted similarity measure. Beberapa definisi dan proposisi yang dijadikan sebagai rujukan dalam penelitian ini diberikan sebagai berikut.

\subsection{Himpunan Interval Value Pythagorean Fuzzy}

Bilangan interval $\bar{y}$ didefinisikan sebagai $\bar{y}=\left[y^{a}, y^{b}\right]=\left\{y^{a} \leq y \leq y^{b}\right\}$ dengan $y^{a}$ dan $y^{b}$ adalah batas bawah dan batas atas dari bilangan interval $\bar{y}$. Jika $y^{a}=y^{b}$, maka $\bar{y}$ adalah bilangan riil. Untuk sebarang dua interval $\left[y^{a}, y^{b}\right]$ dan $\left[z^{a}, z^{b}\right]$, berlaku operasi berikut [14].

1. $\left[y^{a}, y^{b}\right]+\left[z^{a}, z^{b}\right]=\left[y^{a}+y^{a}, z^{b}+z^{b}\right]$

2. $\left[y^{a}, y^{b}\right]-\left[z^{a}, z^{b}\right]=\left[y^{a}-z^{a}, y^{b}-z^{b}\right]$

3. $\left[y^{a}, y^{b}\right] \times\left[z^{a}, z^{b}\right]=\left[y^{*}, z^{*}\right]$, dengan $y^{*}=\min \left(y^{a} z^{a}, y^{a} z^{b}, y^{b} z^{a}, y^{b} z^{b}\right)$ dan $z^{*}=\max \left(y^{a} z^{a}, y^{a} z^{b}, y^{b} z^{a}, y^{b} z^{b}\right)$

4. $\frac{\left[y^{a}, y^{b}\right]}{\left[z^{a}, z^{b}\right]}=\left[y^{a}, y^{b}\right] \times\left[\frac{1}{z^{b}}, \frac{1}{z^{a}}\right], 0 \notin\left[z^{a}, z^{b}\right]$

Bilangan interval telah diaplikasikan dalam berbagai bidang, salah satunya adalah himpunan interval value Pythagorean fuzzy. Himpunan interval value Pythagorean fuzzy menjadi dasar utama dalam penelitian ini untuk membentuk operator agregasi interval value Pythagorean fuzzy yang baru. Berikut diberikan definisi dan beberapa operator yang berlaku pada himpunan interval value Pythagorean fuzzy.

Definisi 1 [15] Misalkan Y adalah himpunan tak kosong. IVPFS I atas Y didefinisikan sebagai

$$
I=\left\{\left(y, \mu_{I}(y), v_{I}(y)\right) \mid y \in Y\right\} .
$$

dimana

$$
\begin{aligned}
& \mu_{I}(y)=\left[\mu_{I}^{a}(y), \mu_{I}^{b}(y)\right] \subset[0,1], \quad \text { dengan } \mu_{I}^{a}(y)=\inf \left(\mu_{I}(y)\right) \text { dan } \mu_{I}^{b}(y)=\sup \left(\mu_{I}(y)\right) \\
& v_{I}(y)=\left[v_{I}^{a}(y), v_{I}^{b}(y)\right] \subset[0,1], \quad \text { dengan } v_{I}^{a}(y)=\inf \left(v_{I}(y)\right) \quad \text { dan } v_{I}^{b}(y)=\sup \left(v_{I}(y)\right)
\end{aligned}
$$

dan $0 \leq\left(\mu_{I}^{b}(y)\right)^{2}+\left(v_{I}^{b}(y)\right)^{2} \leq 1 . \mu_{I}(y)$ dan $v_{I}(y)$ adalah derajat keanggotaan dan derajat non keanggotaan dari $y \in Y$ pada $I . \pi_{I}(y)=\left[\pi_{I}^{a}(y), \pi_{I}^{b}(y)\right]$ adalah derajat ketidakpastian dari $y$ pada $I$ dengan $\pi_{I}^{a}(y)=\sqrt{1-\left(\mu_{I}^{b}(y)\right)^{2}-\left(v_{I}^{b}(y)\right)^{2}}$ dan $\pi_{I}^{b}(y)=\sqrt{1-\left(\mu_{I}^{a}(y)\right)^{2}-\left(v_{I}^{a}(y)\right)^{2}}$. 
Selanjutnya, $I=\left(\left[\mu_{I}^{a}, \mu_{I}^{b}\right],\left[v_{I}^{a}, v_{I}^{b}\right]\right)$ disebut sebagai Interval Value Pythagorean Fuzzy Number (IVPFN).

Definisi 2 [15] Misalkan $I_{1}=\left(\left[\mu_{I_{1}}^{a}, \mu_{I_{1}}^{b}\right],\left[v_{I_{1}}^{a}, v_{I_{1}}^{b}\right]\right)$ dan $I_{2}=\left(\left[\mu_{I_{2}}^{a}, \mu_{I_{2}}^{b}\right],\left[v_{I_{2}}^{a}, v_{I_{2}}^{b}\right]\right)$ adalah dua IVPFN. Relasi antara dua IVPFN didefinisikan sebagai berikut.

1. $I_{1}=I_{2}$ jika dan hanya jika $\mu_{I_{1}}^{a}=\mu_{I_{2}}^{a}, \mu_{I_{1}}^{b}=\mu_{I_{2}}^{b}, v_{I_{1}}^{a}=v_{I_{2}}^{a}$, dan $v_{I_{1}}^{b}=v_{I_{2}}^{b}$.

2. $I_{1} \leq I_{2}$ jika dan hanya jika $\mu_{I_{1}}^{a} \leq \mu_{I_{2}}^{a}, \mu_{I_{1}}^{b} \leq \mu_{I_{2}}^{b}, v_{I_{1}}^{a} \geq v_{I_{2}}^{a}$, dan $v_{I_{1}}^{b} \geq v_{I_{2}}^{b}$.

Definisi 3 [15] Misalkan $I=\left(\left[\mu_{I}^{a}, \mu_{I}^{b}\right],\left[v_{I}^{a}, v_{I}^{b}\right]\right)$ adalah suatu IVPFN. Fungsi score $S(I)$ dan fungsi akurasi $H(I)$ didefinisikan sebagai berikut.

$$
\begin{array}{ll}
S(I)=\frac{1}{2}\left[\left(\mu_{I}^{a}\right)^{2}+\left(\mu_{I}^{b}\right)^{2}-\left(v_{I}^{a}\right)^{2}-\left(v_{I}^{b}\right)^{2}\right], & S(I) \in[-1,1] . \\
H(I)=\frac{1}{2}\left[\left(\mu_{I}^{a}\right)^{2}+\left(\mu_{I}^{b}\right)^{2}+\left(v_{I}^{a}\right)^{2}+\left(v_{I}^{b}\right)^{2}\right], & H(I) \in[0,1] .
\end{array}
$$

Jika $I_{1}, I_{2}$ adalah dua IVPFN, maka:

1. Jika $S\left(I_{1}\right)<S\left(I_{2}\right)$, maka $I_{1}<I_{2}$.

2. Jika $S\left(I_{1}\right)=S\left(I_{2}\right)$, maka:

a. Jika $H\left(I_{1}\right)=H\left(I_{2}\right)$, maka $I_{1}=I_{2}$

b. Jika $H\left(I_{1}\right)<H\left(I_{2}\right)$, maka $I_{1}<I_{2}$

c. Jika $H\left(I_{1}\right)>H\left(I_{2}\right)$, maka $I_{1}>I_{2}$

Definisi 4 [15] Misalkan $I_{1}=\left(\left[\mu_{I_{1}}^{a}, \mu_{I_{1}}^{b}\right],\left[v_{I_{1}}^{a}, v_{I_{1}}^{b}\right]\right)$ dan $I_{2}=\left(\left[\mu_{I_{2}}^{a}, \mu_{I_{2}}^{b}\right],\left[v_{I_{2}}^{a}, v_{I_{2}}^{b}\right]\right)$ adalah dua IVPFN dan $\lambda>0$, maka:

1. $I_{1} \oplus I_{2}=\left(\left[\sqrt{\left(\mu_{I_{1}}^{a}\right)^{2}+\left(\mu_{I_{2}}^{a}\right)^{2}-\left(\mu_{I_{1}}^{a}\right)^{2}\left(\mu_{I_{2}}^{a}\right)^{2}}, \sqrt{\left(\mu_{I_{1}}^{b}\right)^{2}+\left(\mu_{I_{2}}^{b}\right)^{2}-\left(\mu_{I_{1}}^{b}\right)^{2}\left(\mu_{I_{2}}^{b}\right)^{2}}\right],\left[v_{I_{1}}^{a} v_{I_{2}}^{a}, v_{I_{1}}^{b} v_{I_{2}}^{b}\right]\right)$.

2. $I_{1} \otimes I_{2}=\left(\left[\mu_{I_{1}}^{a} \mu_{I_{2}}^{a}, \mu_{I_{1}}^{b} \mu_{I_{2}}^{b}\right],\left[\sqrt{\left(v_{I_{1}}^{a}\right)^{2}+\left(v_{I_{2}}^{a}\right)^{2}-\left(v_{I_{1}}^{a}\right)^{2}\left(v_{I_{2}}^{a}\right)^{2}}, \sqrt{\left(v_{I_{1}}^{b}\right)^{2}+\left(v_{I_{2}}^{b}\right)^{2}-\left(v_{I_{1}}^{b}\right)^{2}\left(v_{I_{2}}^{b}\right)^{2}}\right]\right)$.

3. $\lambda I_{1}=\left(\left[\sqrt{1-\left(1-\left(\mu_{I_{1}}^{a}\right)^{2}\right)^{\lambda}}, \sqrt{1-\left(1-\left(\mu_{I_{1}}^{b}\right)^{2}\right)^{\lambda}}\right],\left[\left(v_{I_{1}}^{a}\right)^{\lambda},\left(v_{I_{1}}^{b}\right)^{\lambda}\right]\right)$.

4. $I_{1}^{\lambda}=\left(\left[\left(\mu_{I_{1}}^{a}\right)^{\lambda},\left(\mu_{I_{1}}^{b}\right)^{\lambda}\right],\left[\sqrt{1-\left(1-\left(v_{I_{1}}^{a}\right)^{2}\right)^{\lambda}}, \sqrt{1-\left(1-\left(v_{I_{1}}^{b}\right)^{2}\right)^{\lambda}}\right]\right)$.

Koleksi IVPFN $I_{i}=\left(\left[\mu_{I_{i}}^{a}, \mu_{I_{i}}^{b}\right],\left[v_{I_{i}}^{a}, v_{I_{i}}^{b}\right]\right)$ untuk $i=1,2, \cdots, n$ diagregasi menggunakan Interval Value Pythagorean Fuzzy Weighted Average (IVPFWA) dan Interval Value Pythagorean Fuzzy Weighted Geometric (IVPFWG). 
Definisi dari kedua operator tersebut diberikan sebagai berikut.

Definisi 5 [10] Misalkan $I_{i}=\left(\left[\mu_{I_{i}}^{a}, \mu_{I_{i}}^{b}\right],\left[v_{I_{i}}^{a}, v_{I_{i}}^{b}\right]\right)$ untuk $i=1,2, \cdots, n$ adalah koleksi IVPFN. Operator IVPFWA didefinisikan sebagai

$$
\phi\left(I_{1}, I_{2}, \cdots, I_{n}\right)=\left(\left[\sqrt{1-\prod_{i=1}^{n}\left(1-\left(\mu_{I_{i}}^{a}\right)^{2}\right)^{\alpha_{i}}}, \sqrt{\left.1-\prod_{i=1}^{n}\left(1-\left(\mu_{I_{i}}^{b}\right)^{2}\right)^{\alpha_{i}}\right]},\left[\prod_{i=1}^{n}\left(v_{I_{i}}^{a}\right)^{\alpha_{i}}, \prod_{i=1}^{n}\left(v_{I_{i}}^{b}\right)^{\alpha_{i}}\right]\right) .\right.
$$

Operator IVPFWG didefinisikan sebagai

$$
\psi\left(I_{1}, I_{2}, \cdots, I_{n}\right)=\left(\left[\prod_{i=1}^{n}\left(\mu_{I_{i}}^{a}\right)^{\alpha_{i}}, \prod_{i=1}^{n}\left(\mu_{I_{i}}^{b}\right)^{\alpha_{i}}\right],\left[\sqrt{1-\prod_{i=1}^{n}\left(1-\left(v_{I_{i}}^{a}\right)^{2}\right)^{\alpha_{i}}}, \sqrt{1-\prod_{i=1}^{n}\left(1-\left(v_{I_{i}}^{b}\right)^{2}\right)^{\alpha_{i}}}\right]\right) .
$$

dengan $\alpha_{i}$ adalah pembobot dari $I_{i}$ untuk $i=1,2, \cdots, n$ dan $\alpha_{i} \in[0,1], \sum_{i=1}^{n} \alpha_{i}=1$.

\subsection{Similarity Measure}

Konsep similarity measure dalam penelitian ini berperan sebagai metode verifikasi hasil dari operator agregasi interval value Pythagorean fuzzy. Konsep similarity measure berperan untuk menentukan tingkat efektivitas dan akurasi dari operator agregasi yang digunakan. Berikut diberikan definisi similarity measure

Definisi 6 [13] Misalkan $Y$ adalah himpunan tak kosong dan $I_{1}, I_{2}$ adalah IVPFS atas $Y$. Similarity measure antara $I_{1}$ dan $I_{2}$ adalah fungsi $S M: Y \times Y \rightarrow[0,1]$ yang memenuhi aksioma berikut:

1. $0 \leq S M\left(I_{1}, I_{2}\right) \leq 1$.

2. $\operatorname{SM}\left(I_{1}, I_{2}\right)=1$ jika $I_{1}=I_{2}$.

3. $\operatorname{SM}\left(I_{1}, I_{2}\right)=\operatorname{SM}\left(I_{2}, I_{1}\right)$.

4. $S M\left(I_{1}, I_{3}\right) \leq S M\left(I_{1}, I_{2}\right)$ dan $S M\left(I_{1}, I_{3}\right) \leq S M\left(I_{2}, I_{3}\right)$ jika $I_{1} \subset I_{2} \subset I_{3}$ untuk sebarang IVPFS I $I_{3}$.

Proposisi 7 [13] Misalkan $Y=\left\{y_{1}, y_{2}, \cdots, y_{n}\right\}$ adalah suatu himpunan dan $I_{1}, I_{2}$ adalah dua IVPFS atas $Y$. Similarity measure antara $I_{1}$ dan $I_{2}$ adalah

$$
S M\left(I_{1}, I_{2}\right)=\frac{1}{2 n} \sum_{i=1}^{n}\left(\frac{\min \left(\mu_{I_{1}}\left(y_{i}\right), \mu_{I_{2}}\left(y_{i}\right)\right)}{\max \left(\mu_{I_{1}}\left(y_{i}\right), \mu_{I_{2}}\left(y_{i}\right)\right)}+\frac{\min \left(v_{I_{1}}\left(y_{i}\right), v_{I_{2}}\left(y_{i}\right)\right)}{\max \left(v_{I_{1}}\left(y_{i}\right), v_{I_{2}}\left(y_{i}\right)\right)}\right)
$$

yang memenuhi aksioma pada Definisi 6, dengan

$$
\begin{array}{ll}
\mu_{I_{1}}\left(y_{i}\right)=\left[\mu_{I_{1}}^{a}\left(y_{i}\right), \mu_{I_{1}}^{b}\left(y_{i}\right)\right] \text { dan } & v_{I_{1}}\left(y_{i}\right)=\left[v_{I_{1}}^{a}\left(y_{i}\right), v_{I_{1}}^{b}\left(y_{i}\right)\right], \\
\mu_{I_{2}}\left(y_{i}\right)=\left[\mu_{I_{2}}^{a}\left(y_{i}\right), \mu_{I_{2}}^{b}\left(y_{i}\right)\right] \text { dan } & v_{I_{2}}\left(y_{i}\right)=\left[v_{I_{2}}^{a}\left(y_{i}\right), v_{I_{2}}^{b}\left(y_{i}\right)\right]
\end{array}
$$


Bukti: Berdasarkan verifikasi, $S M\left(I_{1}, I_{2}\right)$ memenuhi aksioma 1-3 pada Definisi 6. Selanjutnya akan dibuktikan untuk aksioma 4. Misalkan $I_{1} \subset I_{2} \subset I_{3}$. Berdasarkan Definisi 2 diperoleh

$$
\begin{array}{lll}
\mu_{I_{1}}^{a}\left(y_{i}\right) \leq \mu_{I_{2}}^{a}\left(y_{i}\right) \leq \mu_{I_{3}}^{a}\left(y_{i}\right) & \text { dan } & \mu_{I_{1}}^{b}\left(y_{i}\right) \leq \mu_{I_{2}}^{b}\left(y_{i}\right) \leq \mu_{I_{3}}^{b}\left(y_{i}\right) \\
v_{I_{1}}^{a}\left(y_{i}\right) \geq v_{I_{2}}^{a}\left(y_{i}\right) \geq v_{I_{3}}^{a}\left(y_{i}\right) & \text { dan } \quad v_{I_{1}}^{b}\left(y_{i}\right) \geq v_{I_{2}}^{b}\left(y_{i}\right) \geq v_{I_{3}}^{b}\left(y_{i}\right)
\end{array}
$$

Untuk setiap $y_{i} \in Y$. Selanjutnya,

$$
\begin{array}{r}
\min \left\{\left[\mu_{I_{1}}^{a}\left(y_{i}\right), \mu_{I_{1}}^{b}\left(y_{i}\right)\right],\left[\mu_{I_{2}}^{a}\left(y_{i}\right), \mu_{I_{2}}^{b}\left(y_{i}\right)\right]\right\}=\left[\mu_{I_{1}}^{a}\left(y_{i}\right), \mu_{I_{1}}^{b}\left(y_{i}\right)\right] \\
\max \left\{\left[\mu_{I_{1}}^{a}\left(y_{i}\right), \mu_{I_{1}}^{b}\left(y_{i}\right)\right],\left[\mu_{I_{2}}^{a}\left(y_{i}\right), \mu_{I_{2}}^{b}\left(y_{i}\right)\right]\right\}=\left[\mu_{I_{2}}^{a}\left(y_{i}\right), \mu_{I_{2}}^{b}\left(y_{i}\right)\right] \\
\min \left\{\left[v_{I_{1}}^{a}\left(y_{i}\right), v_{I_{1}}^{b}\left(y_{i}\right)\right],\left[v_{I_{2}}^{a}\left(y_{i}\right), v_{I_{2}}^{b}\left(y_{i}\right)\right]\right\}=\left[v_{I_{2}}^{a}\left(y_{i}\right), v_{I_{2}}^{b}\left(y_{i}\right)\right] \\
\max \left\{\left[v_{I_{1}}^{a}\left(y_{i}\right), v_{I_{1}}^{b}\left(y_{i}\right)\right],\left[v_{I_{2}}^{a}\left(y_{i}\right), v_{I_{2}}^{b}\left(y_{i}\right)\right]\right\}=\left[v_{I_{1}}^{a}\left(y_{i}\right), v_{I_{1}}^{b}\left(y_{i}\right)\right]
\end{array}
$$

dan

$$
\begin{aligned}
& S M\left(I_{1}, I_{2}\right)=\frac{1}{2 n} \sum_{i=1}^{n}\left(\frac{\min \left(\mu_{I_{1}}\left(y_{i}\right), \mu_{I_{2}}\left(y_{i}\right)\right)}{\max \left(\mu_{I_{1}}\left(y_{i}\right), \mu_{I_{2}}\left(y_{i}\right)\right)}+\frac{\min \left(v_{I_{1}}\left(y_{i}\right), v_{I_{2}}\left(y_{i}\right)\right)}{\max \left(v_{I_{1}}\left(y_{i}\right), v_{I_{2}}\left(y_{i}\right)\right)}\right) \\
& =\frac{1}{2 n} \sum_{i=1}^{n}\left(\begin{array}{c}
\frac{\min \left(\left[\mu_{I_{1}}^{a}\left(y_{i}\right), \mu_{I_{1}}^{b}\left(y_{i}\right)\right],\left[\mu_{I_{2}}^{a}\left(y_{i}\right), \mu_{I_{2}}^{b}\left(y_{i}\right)\right]\right)}{\max \left(\left[\mu_{I_{1}}^{a}\left(y_{i}\right), \mu_{I_{1}}^{b}\left(y_{i}\right)\right],\left[\mu_{I_{2}}^{a}\left(y_{i}\right), \mu_{I_{2}}^{b}\left(y_{i}\right)\right]\right)} \\
+\frac{\min \left(\left[v_{I_{1}}^{a}\left(y_{i}\right), v_{I_{1}}^{b}\left(y_{i}\right)\right],\left[v_{I_{2}}^{a}\left(y_{i}\right), v_{I_{2}}^{b}\left(y_{i}\right)\right]\right)}{\max \left(\left[v_{I_{1}}^{a}\left(y_{i}\right), v_{I_{1}}^{b}\left(y_{i}\right)\right],\left[v_{I_{2}}^{a}\left(y_{i}\right), v_{I_{2}}^{b}\left(y_{i}\right)\right]\right)}
\end{array}\right) \\
& =\frac{1}{2 n} \sum_{i=1}^{n}\left(\frac{\left[\mu_{I_{1}}^{a}\left(y_{i}\right), \mu_{I_{1}}^{b}\left(y_{i}\right)\right]}{\left[\mu_{I_{2}}^{a}\left(y_{i}\right), \mu_{I_{2}}^{b}\left(y_{i}\right)\right]}+\frac{\left[v_{I_{2}}^{a}\left(y_{i}\right), v_{I_{2}}^{b}\left(y_{i}\right)\right]}{\left[v_{I_{1}}^{a}\left(y_{i}\right), v_{I_{1}}^{b}\left(y_{i}\right)\right]}\right) \\
& =\frac{1}{2 n} \sum_{i=1}^{n}\left(\left[\frac{\mu_{I_{1}}^{a}\left(y_{i}\right)}{\mu_{I_{2}}^{b}\left(y_{i}\right)}, \frac{\mu_{I_{1}}^{b}\left(y_{i}\right)}{\mu_{I_{2}}^{a}\left(y_{i}\right)}\right]+\left[\frac{v_{I_{2}}^{a}\left(y_{i}\right)}{v_{I_{1}}^{b}\left(y_{i}\right)}, \frac{v_{I_{2}}^{b}\left(y_{i}\right)}{v_{I_{1}}^{a}\left(y_{i}\right)}\right]\right) \\
& =\frac{1}{2 n} \sum_{i=1}^{n}\left(\left[\frac{\mu_{I_{1}}^{a}\left(y_{i}\right)}{\mu_{I_{2}}^{b}\left(y_{i}\right)}+\frac{v_{I_{2}}^{a}\left(y_{i}\right)}{v_{I_{1}}^{b}\left(y_{i}\right)}, \frac{\mu_{I_{1}}^{b}\left(y_{i}\right)}{\mu_{I_{2}}^{a}\left(y_{i}\right)}+\frac{v_{I_{2}}^{b}\left(y_{i}\right)}{v_{I_{1}}^{a}\left(y_{i}\right)}\right]\right)
\end{aligned}
$$

Dengan cara yang sama, diperoleh

$$
\begin{aligned}
& S M\left(I_{1}, I_{3}\right)=\frac{1}{2 n} \sum_{i=1}^{n}\left(\left[\frac{\mu_{I_{1}}^{a}\left(y_{i}\right)}{\mu_{I_{3}}^{b}\left(y_{i}\right)}+\frac{v_{I_{3}}^{a}\left(y_{i}\right)}{v_{I_{1}}^{b}\left(y_{i}\right)}, \frac{\mu_{I_{1}}^{b}\left(y_{i}\right)}{\mu_{I_{3}}^{a}\left(y_{i}\right)}+\frac{v_{I_{3}}^{b}\left(y_{i}\right)}{v_{I_{1}}^{a}\left(y_{i}\right)}\right]\right) \\
& S M\left(I_{2}, I_{3}\right)=\frac{1}{2 n} \sum_{i=1}^{n}\left(\left[\frac{\mu_{I_{2}}^{a}\left(y_{i}\right)}{\mu_{I_{3}}^{b}\left(y_{i}\right)}+\frac{v_{I_{3}}^{a}\left(y_{i}\right)}{v_{I_{2}}^{b}\left(y_{i}\right)}, \frac{\mu_{I_{2}}^{b}\left(y_{i}\right)}{\mu_{I_{3}}^{a}\left(y_{i}\right)}+\frac{v_{I_{3}}^{b}\left(y_{i}\right)}{v_{I_{2}}^{a}\left(y_{i}\right)}\right]\right)
\end{aligned}
$$

Selanjutnya, untuk $S M\left(I_{1}, I_{3}\right)$ diperoleh 
$\left(\frac{\mu_{I_{1}}^{a}\left(y_{i}\right)}{\mu_{I_{3}}^{b}\left(y_{i}\right)}+\frac{v_{I_{3}}^{a}\left(y_{i}\right)}{v_{I_{1}}^{b}\left(y_{i}\right)}\right) \leq\left(\frac{\mu_{I_{1}}^{a}\left(y_{i}\right)}{\mu_{I_{2}}^{b}\left(y_{i}\right)}+\frac{v_{I_{2}}^{a}\left(y_{i}\right)}{v_{I_{1}}^{b}\left(y_{i}\right)}\right)$ dan $\left(\frac{\mu_{I_{1}}^{b}\left(y_{i}\right)}{\mu_{I_{3}}^{a}\left(y_{i}\right)}+\frac{v_{I_{3}}^{b}\left(y_{i}\right)}{v_{I_{1}}^{a}\left(y_{i}\right)}\right) \leq\left(\frac{\mu_{I_{1}}^{b}\left(y_{i}\right)}{\mu_{I_{2}}^{a}\left(y_{i}\right)}+\frac{v_{I_{2}}^{b}\left(y_{i}\right)}{v_{I_{1}}^{a}\left(y_{i}\right)}\right)$

dan

$\left(\frac{\mu_{I_{1}}^{a}\left(y_{i}\right)}{\mu_{I_{3}}^{b}\left(y_{i}\right)}+\frac{v_{I_{3}}^{a}\left(y_{i}\right)}{v_{I_{1}}^{b}\left(y_{i}\right)}\right) \leq\left(\frac{\mu_{I_{2}}^{a}\left(y_{i}\right)}{\mu_{I_{3}}^{b}\left(y_{i}\right)}+\frac{v_{I_{3}}^{a}\left(y_{i}\right)}{v_{I_{2}}^{b}\left(y_{i}\right)}\right) \operatorname{dan}\left(\frac{\mu_{I_{1}}^{b}\left(y_{i}\right)}{\mu_{I_{3}}^{a}\left(y_{i}\right)}+\frac{v_{I_{3}}^{b}\left(y_{i}\right)}{v_{I_{1}}^{a}\left(y_{i}\right)}\right) \leq\left(\frac{\mu_{I_{2}}^{b}\left(y_{i}\right)}{\mu_{I_{3}}^{a}\left(y_{i}\right)}+\frac{v_{I_{3}}^{b}\left(y_{i}\right)}{v_{I_{2}}^{a}\left(y_{i}\right)}\right)$

Akibatnya diperoleh $S M\left(I_{1}, I_{3}\right) \leq S M\left(I_{1}, I_{2}\right)$ dan $S M\left(I_{1}, I_{3}\right) \leq S M\left(I_{2}, I_{3}\right)$. Sehingga $S M\left(I_{1}, I_{2}\right)$ memenuhi aksioma 4.

Proposisi 8 [13] Misalkan $Y=\left\{y_{1}, y_{2}, \cdots, y_{n}\right\}$ adalah himpunan dan $I_{1}, I_{2}$ adalah dua IVPFS. Weighted similarity measure antara $I_{1}$ dan $I_{2}$ adalah

$$
S M^{*}\left(I_{1}, I_{2}\right)=\sum_{i=1}^{n} \alpha_{i}\left(\delta \frac{\min \left(\mu_{I_{1}}\left(y_{i}\right), \mu_{I_{2}}\left(y_{i}\right)\right)}{\max \left(\mu_{I_{1}}\left(y_{i}\right), \mu_{I_{2}}\left(y_{i}\right)\right)}+\gamma \frac{\min \left(v_{I_{1}}\left(y_{i}\right), v_{I_{2}}\left(y_{i}\right)\right)}{\max \left(v_{I_{1}}\left(y_{i}\right), v_{I_{2}}\left(y_{i}\right)\right)}\right) .
$$

yang memenuhi aksioma pada Definisi 6, dengan

$\mu_{I_{1}}\left(y_{i}\right)=\left[\mu_{I_{1}}^{a}\left(y_{i}\right), \mu_{I_{1}}^{b}\left(y_{i}\right)\right]$ dan $v_{I_{1}}\left(y_{i}\right)=\left[v_{I_{1}}^{a}\left(y_{i}\right), v_{I_{1}}^{b}(y)\right]$

$\mu_{I_{2}}\left(y_{i}\right)=\left[\mu_{I_{2}}^{a}\left(y_{i}\right), \mu_{I_{2}}^{b}\left(y_{i}\right)\right]$ dan $v_{I_{2}}\left(y_{i}\right)=\left[v_{I_{2}}^{a}\left(y_{i}\right), v_{I_{2}}^{b}\left(y_{i}\right)\right]$

$\alpha_{i}$ adalah pembobot dari $y_{i}$ untuk $i=1,2, \cdots, n$ dengan $\alpha_{i} \in[0,1]$ dan $\sum_{i=1}^{n} \alpha_{i}=1$. $\delta$ dan $\gamma$ adalah pembobot dari $\mu$ dan $v$ dengan $\delta, \gamma \in[0,1]$ dan $\delta+\gamma=1$.

IVPFS diaplikasikan dalam berbagai bidang pengambilan keputusan, salah satunya adalah MCDM. Koleksi informasi fuzzy $A=\left\{A_{i} \mid i=1,2, \cdots, n\right\}$ berdasarkan kriteria $C=$ $\left\{C_{j} \mid j=1,2, \cdots, m\right\}$ dalam kasus MCDM dinyatakan dalam IVPFN. Dalam proses MCDM, terdapat suatu konsep yang berperan penting dalam pengambilan keputusan, yaitu konsep interval value Pythagorean fuzzy ideal solution $\left(A^{*}\right)$. Konsep tersebut digunakan untuk mengidentifikasi alternatif $A_{i} \in A$ yang terbaik. Dalam proses pengambilan keputusan yang sebenarnya, konsep ini tidak ada. Dengan kata lain, $A^{*}$ biasanya merupakan alternatif yang tidak layak, yaitu $A^{*} \notin A$. Sebaliknya, $A^{*}$ merupakan alternatif yang optimal dalam kasus MCDM.

Nilai $A^{*}$ ditentukan dengan dua jenis kriteria, yaitu kriteria jenis manfaat dan biaya. $A^{*}$ didefinisikan sebagai berikut.

$$
A^{*}=\left\{A_{1}^{*}, A_{2}^{*}, \cdots, A_{m}^{*}\right\} .
$$

dengan $A_{j}^{*}=\left\{C_{j}, \max _{\mathrm{i}}\left(A_{i j}\right) \mid j=1,2, \cdots, m\right\}$ untuk kriteria jenis manfaat dan $A_{j}^{*}=$ $\left\{C_{j}, \min _{\mathrm{i}}\left(A_{i j}\right) \mid j=1,2, \cdots, m\right\}$ untuk kriteria jenis biaya [13]. 


\subsection{Generalized Parameter}

Generalized Parameter (GP) merupakan konsep yang digunakan untuk menilai akurasi suatu informasi fuzzy. GP dinyatakan dengan cara yang sama seperti informasi fuzzy. Jika informasi fuzzy dinyatakan dengan IVPFS, maka GP juga dinyatakan dalam IVPFS. Berikut diberikan definisi GP.

Definisi 9 [11] Misalkan $Y$ adalah himpunan tak kosong dan $I=\left\{\left(y, \mu_{I}(y), v_{I}(y)\right) \mid y \in Y\right\}$ dengan $\mu_{I}(y)$ dan $v_{I}(y)$ yang diberikan seperti pada Definisi 1 adalah IVPFS atas Y. Generalized Parameter (GP) dari I didefinisikan sebagai

$$
\epsilon=\left(\mu_{\epsilon}, v_{\epsilon}\right) \text {. }
$$

dengan $\mu_{\epsilon}$ adalah derajat akurasi informasi dan $v_{\epsilon}$ adalah derajat oposisi akurasi informasi pada I. Selanjutnya, I bersama dengan GP dituliskan sebagai

$$
I_{\epsilon}=\left\{\left\{\left(y, \mu_{I}(y), v_{I}(y)\right) \mid y \in Y\right\},\left(\mu_{\epsilon}, v_{\epsilon}\right)\right\}
$$

Group Generalized Parameter (GGP) dari I didefinisikan sebagai

$$
\epsilon=\left\{\epsilon_{1}, \epsilon_{2}, \cdots, \epsilon_{l}\right\}=\left\{\left(\mu_{\epsilon_{1}}, v_{\epsilon_{1}}\right),\left(\mu_{\epsilon_{2}}, v_{\epsilon_{2}}\right), \cdots,\left(\mu_{\epsilon_{l}}, v_{\epsilon_{l}}\right)\right\}
$$

Selanjutnya, I bersama dengan GGP dituliskan sebagai

$$
I_{\epsilon}=\left\{\left\{\left(y, \mu_{I}(y), v_{I}(y)\right) \mid y \in Y\right\},\left\{\left(\mu_{\epsilon_{1}}, v_{\epsilon_{1}}\right),\left(\mu_{\epsilon_{2}}, v_{\epsilon_{2}}\right), \cdots,\left(\mu_{\epsilon_{l}}, v_{\epsilon_{l}}\right)\right\}\right\}
$$

\section{Hasil dan Pembahasan}

Operator agregasi group generalized interval value Pythagorean fuzzy merupakan suatu operator yang digunakan untuk mengagregasi informasi fuzzy dan GGP yang dinyatakan dalam IVPFS. Hal itu mengakibatkan bahwa operator agregasi group generalized interval value Pythagorean fuzzy dibangun dari dua konsep, yaitu konsep GGP dan IVPFS. Berikut diberikan definisi dari beberapa operator agregasi group generalized interval value Pythagorean fuzzy.

\subsection{Operator Agregasi Group Generalized Interval Value Pythagorean Fuzzy}

Definisi 10 Misal diberikan suatu informasi fuzzy $I_{i}=\left(\left[\mu_{I_{i}}^{a}, \mu_{I_{i}}^{b}\right],\left[v_{I_{i}}^{a}, v_{I_{i}}^{b}\right]\right)$ untuk $i=1,2, \cdots, n$ dan $G G P \epsilon_{k}=\left(\left[\mu_{\epsilon_{k}}^{a}, \mu_{\epsilon_{k}}^{b}\right],\left[v_{\epsilon_{k}}^{a}, v_{\epsilon_{k}}^{b}\right]\right)$ untuk $k=1,2, \cdots, l . \Omega^{n}$ adalah himpunan yang memuat koleksi informasi fuzzy $I_{i}$ dan $\Omega^{l}$ adalah himpunan yang memuat koleksi GGP $\epsilon_{k}$. Operator GGIVPFWA adalah fungsi $\Phi: \Omega^{n} \times \Omega^{l} \rightarrow \Omega$ dengan

$$
\begin{aligned}
\Phi\left(\left(I_{1}, I_{2}, \cdots, I_{n}\right),\left(\epsilon_{1}, \epsilon_{2}, \cdots, \epsilon_{l}\right)\right) & =\phi\left(I_{1}, I_{2}, \cdots, I_{n}\right) \otimes \phi\left(\epsilon_{1}, \epsilon_{2}, \cdots, \epsilon_{l}\right) \\
& =\left(\alpha_{1} I_{1} \oplus \alpha_{2} I_{2} \oplus \cdots \oplus \alpha_{n} I_{n}\right) \otimes\left(\beta_{1} \epsilon_{1} \oplus \beta_{2} \epsilon_{2} \oplus \cdots \oplus \beta_{l} \epsilon_{l}\right) .
\end{aligned}
$$


Operator GGIVPFWG adalah pemetaan $\Psi: \Omega^{n} \times \Omega^{l} \rightarrow \Omega$ dengan

$$
\begin{aligned}
\Phi\left(\left(I_{1}, I_{2}, \cdots, I_{n}\right),\left(\epsilon_{1}, \epsilon_{2}, \cdots, \epsilon_{l}\right)\right) & =\psi\left(I_{1}, I_{2}, \cdots, I_{n}\right) \otimes \psi\left(\epsilon_{1}, \epsilon_{2}, \cdots, \epsilon_{l}\right) \\
& =\left(I_{1}^{\alpha_{1}} \otimes I_{2}^{\alpha_{2}} \otimes \cdots \otimes I_{n}^{\alpha_{n}}\right) \otimes\left(\epsilon_{1}^{\beta_{1}} \otimes \epsilon_{2}^{\beta_{2}} \otimes \cdots \otimes \epsilon_{l}^{\beta_{l}}\right) .
\end{aligned}
$$

$\alpha_{i}$ adalah pembobot atas $I_{i}$ dengan $\alpha_{i} \in[0,1]$ dan $\sum_{i=1}^{n} \alpha_{i}=1$. $\beta_{k}$ adalah pembobot atas $\epsilon_{k}$ dengan $\beta_{k} \in[0,1]$ dan $\sum_{k=1}^{l} \beta_{k}=1$. Jika l=1, maka hanya ada satu GP. Sehingga operator GGIVPFWA menjadi operator GIVPFWA. Sama halnya dengan operator GGIVPFWG yang menjadi operator GIVPFWG.

Teorema 11 Jika $I_{i}=\left(\left[\mu_{I_{i}}^{a}, \mu_{I_{i}}^{b}\right],\left[v_{I_{i}}^{a}, v_{I_{i}}^{b}\right]\right)$ untuk $i=1,2, \cdots, n$ adalah $n$ IVPFN dan $\epsilon_{k}=$ $\left(\left[\mu_{\epsilon_{k}}^{a}, \mu_{\epsilon_{k}}^{b}\right],\left[\nu_{\epsilon_{k}}^{a}, v_{\epsilon_{k}}^{b}\right]\right)$ untuk $k=1,2, \cdots, l$ adalah $l$ IVPFN, maka operator GGIVPFWA didefinisikan sebagai

$$
\begin{aligned}
& \Phi\left(\left(I_{1}, I_{2}, \cdots, I_{n}\right),\left(\epsilon_{1}, \epsilon_{2}, \cdots, \epsilon_{l}\right)\right) \\
& =\phi\left(I_{1}, I_{2}, \cdots, I_{n}\right) \otimes \phi\left(\epsilon_{1}, \epsilon_{2}, \cdots, \epsilon_{l}\right) \\
& =\left(\left[\sqrt{1-\prod_{i=1}^{n}\left(1-\left(\mu_{I_{i}}^{a}\right)^{2}\right)^{\alpha_{i}}}, \sqrt{1-\prod_{i=1}^{n}\left(1-\left(\mu_{I_{i}}^{b}\right)^{2}\right)^{\alpha_{i}}}\right],\left[\prod_{i=1}^{n}\left(v_{I_{i}}^{a}\right)^{\alpha_{i}}, \prod_{i=1}^{n}\left(v_{I_{i}}^{b}\right)^{\alpha_{i}}\right]\right) \\
& \otimes\left(\left[\sqrt{1-\prod_{k=1}^{l}\left(1-\left(\mu_{\epsilon_{k}}^{a}\right)^{2}\right)^{\beta_{k}}}, \sqrt{\left.1-\prod_{k=1}^{l}\left(1-\left(\mu_{\epsilon_{k}}^{b}\right)^{2}\right)^{\beta_{k}}\right]},\left[\prod_{k=1}^{l}\left(v_{\epsilon_{k}}^{a}\right)^{\beta_{k}}, \prod_{k=1}^{l}\left(v_{\epsilon_{k}}^{b}\right)^{\beta_{k}}\right]\right)\right. \\
& =\left(\begin{array}{c}
{\left[\begin{array}{c}
\sqrt{\left(1-\prod_{i=1}^{n}\left(1-\left(\mu_{I_{i}}^{a}\right)^{2}\right)^{\alpha_{i}}\right)\left(1-\prod_{k=1}^{l}\left(1-\left(\mu_{\epsilon_{k}}^{a}\right)^{2}\right)^{\beta_{k}}\right)}, \\
{\left[\sqrt{\left(1-\prod_{i=1}^{n}\left(1-\left(\mu_{I_{i}}^{b}\right)^{2}\right)^{\alpha_{i}}\right)\left(1-\prod_{k=1}^{l}\left(1-\left(\mu_{\epsilon_{k}}^{b}\right)^{2}\right)^{\beta_{k}}\right)}\right]}
\end{array}\right.} \\
{\left[\sqrt{\left(\prod_{i=1}^{n}\left(v_{I_{i}}^{a}\right)^{\alpha_{i}}\right)^{2}+\left(\prod_{k=1}^{l}\left(v_{\epsilon_{k}}^{a}\right)^{\beta_{k}}\right)^{2}-\left(\prod_{i=1}^{n}\left(v_{I_{i}}^{a}\right)^{\alpha_{i}}\right)^{2}\left(\prod_{k=1}^{l}\left(v_{\epsilon_{k}}^{a}\right)^{\beta_{k}}\right)^{2}},\right.} \\
\left(\prod_{i=1}^{n}\left(v_{I_{i}}^{b}\right)^{\alpha_{i}}\right)^{2}+\left(\prod_{k=1}^{l}\left(v_{\epsilon_{k}}^{b}\right)^{\beta_{k}}\right)^{2}-\left(\prod_{i=1}^{n}\left(v_{I_{i}}^{b}\right)^{\alpha_{i}}\right)^{2}\left(\prod_{k=1}^{l}\left(v_{\epsilon_{k}}^{b}\right)^{\beta_{k}}\right)^{2}
\end{array}\right] .
\end{aligned}
$$

dan operator GGIVPFWG didefinisikan sebagai

$$
\begin{aligned}
& \Psi\left(\left(I_{1}, I_{2}, \cdots, I_{n}\right),\left(\epsilon_{1}, \epsilon_{2}, \cdots, \epsilon_{l}\right)\right) \\
& =\psi\left(I_{1}, I_{2}, \cdots, I_{n}\right) \otimes \psi\left(\epsilon_{1}, \epsilon_{2}, \cdots, \epsilon_{l}\right) \\
& =\left(\left[\prod_{i=1}^{n}\left(\mu_{I_{i}}^{a}\right)^{\alpha_{i}}, \prod_{i=1}^{n}\left(\mu_{I_{i}}^{b}\right)^{\alpha_{i}}\right],\left[\sqrt{1-\prod_{i=1}^{n}\left(1-\left(v_{I_{i}}^{a}\right)^{2}\right)^{\alpha_{i}}}, \sqrt{1-\prod_{i=1}^{n}\left(1-\left(v_{I_{i}}^{b}\right)^{2}\right)^{\alpha_{i}}}\right]\right) \\
& \otimes\left(\left[\prod_{k=1}^{l}\left(\mu_{\epsilon_{k}}^{a}\right)^{\beta_{k}}, \prod_{k=1}^{l}\left(\mu_{\epsilon_{k}}^{b}\right)^{\beta_{k}}\right],\left[\sqrt{1-\prod_{k=1}^{l}\left(1-\left(v_{\epsilon_{k}}^{a}\right)^{2}\right)^{\beta_{k}}}, \sqrt{1-\prod_{k=1}^{l}\left(1-\left(v_{\epsilon_{k}}^{b}\right)^{2}\right)^{\beta_{k}}}\right]\right)
\end{aligned}
$$




$$
=\left(\left[\begin{array}{l}
{\left[\left(\prod_{i=1}^{n}\left(\mu_{I_{i}}^{a}\right)^{\alpha_{i}}\right)\left(\prod_{k=1}^{l}\left(\mu_{\epsilon_{k}}^{a}\right)^{\beta_{k}}\right),\left(\prod_{i=1}^{n}\left(\mu_{I_{i}}^{b}\right)^{\alpha_{i}}\right)\left(\prod_{k=1}^{l}\left(\mu_{\epsilon_{k}}^{b}\right)^{\beta_{k}}\right)\right.}
\end{array}\right],\right.
$$

Bukti: Teorema 11 hanya akan dibuktikan untuk Persamaan 13 menggunakan induksi matematika. Untuk Persamaan 13, misalkan $n=1$ dan $l=1$ maka

$$
\begin{aligned}
\Phi\left(I_{1}, \epsilon_{1}\right) & =\left(\left[\mu_{I_{1}}^{a}, \mu_{I_{1}}^{b}\right],\left[v_{I_{1}}^{a}, v_{I_{1}}^{b}\right]\right) \otimes\left(\left[\mu_{\epsilon_{1}}^{a}, \mu_{\epsilon_{1}}^{b}\right],\left[v_{\epsilon_{1}}^{a}, v_{\epsilon_{1}}^{b}\right]\right) \\
& =\left(\left[\mu_{I_{1}}^{a} \mu_{\epsilon_{1}}^{a}, \mu_{I_{1}}^{b} \mu_{\epsilon_{1}}^{b}\right],\left[\sqrt{\left(v_{I_{1}}^{a}\right)^{2}+\left(v_{\epsilon_{1}}^{a}\right)^{2}-\left(v_{I_{1}}^{a}\right)^{2}\left(v_{\epsilon_{1}}^{a}\right)^{2}}, \sqrt{\left(v_{I_{1}}^{b}\right)^{2}+\left(v_{\epsilon_{1}}^{b}\right)^{2}-\left(v_{I_{1}}^{b}\right)^{2}\left(v_{\epsilon_{1}}^{b}\right)^{2}}\right]\right)
\end{aligned}
$$

Asumsikan Persamaan 13 benar untuk $n=p$ dan $l=q$, sehingga

$$
\begin{aligned}
& \Phi\left(\left(I_{1}, I_{2}, \cdots, I_{p}\right),\left(\epsilon_{1}, \epsilon_{2}, \cdots, \epsilon_{q}\right)\right) \\
& =\left(\begin{array}{c}
{\left[\begin{array}{c}
\sqrt{\left(1-\prod_{i=1}^{p}\left(1-\left(\mu_{I_{i}}^{a}\right)^{2}\right)^{\alpha_{i}}\right)\left(1-\prod_{k=1}^{q}\left(1-\left(\mu_{\epsilon_{k}}^{a}\right)^{2}\right)^{\beta_{k}}\right)}, \\
{\left[\sqrt{\left(1-\prod_{i=1}^{p}\left(1-\left(\mu_{I_{i}}^{b}\right)^{2}\right)^{\alpha_{i}}\right)\left(1-\prod_{k=1}^{q}\left(1-\left(\mu_{\epsilon_{k}}^{b}\right)^{2}\right)^{\beta_{k}}\right)}\right]}
\end{array}\right.} \\
{\left[\sqrt{\left(\prod_{i=1}^{p}\left(v_{I_{i}}^{a}\right)^{\alpha_{i}}\right)^{2}+\left(\prod_{k=1}^{q}\left(v_{\epsilon_{k}}^{a}\right)^{\beta_{k}}\right)^{2}-\left(\prod_{i=1}^{p}\left(v_{I_{i}}^{a}\right)^{\alpha_{i}}\right)^{2}\left(\prod_{k=1}^{q}\left(v_{\epsilon_{k}}^{a}\right)^{\beta_{k}}\right)^{2}},\right.}
\end{array}\right)
\end{aligned}
$$

Sehingga untuk $n=p+1$ dan $l=q+1$ diperoleh

$$
\begin{aligned}
& \left(\left(I_{1}, I_{2}, \cdots, I_{p}, I_{p+1}\right),\left(\epsilon_{1}, \epsilon_{2}, \cdots, \epsilon_{q}, \epsilon_{q+1}\right)\right) \\
= & \phi\left(I_{1}, I_{2}, \cdots, I_{p}, I_{p+1}\right) \otimes \phi\left(\epsilon_{1}, \epsilon_{2}, \cdots, \epsilon_{q}, \epsilon_{q+1}\right) \\
= & \left(\left[\sqrt{\left.\left.1-\prod_{i=1}^{p+1}\left(1-\left(\mu_{I_{i}}^{a}\right)^{2}\right)^{\alpha_{i}}, \sqrt{1-\prod_{i=1}^{p+1}\left(1-\left(\mu_{I_{i}}^{b}\right)^{2}\right)^{\alpha_{i}}}\right],\left[\prod_{i=1}^{p+1}\left(v_{I_{i}}^{a}\right)^{\alpha_{i}}, \prod_{i=1}^{p+1}\left(v_{I_{i}}^{b}\right)^{\alpha_{i}}\right]\right)}\right.\right. \\
& \otimes\left(\left[\sqrt{1-\prod_{k=1}^{q+1}\left(1-\left(\mu_{\epsilon_{k}}^{a}\right)^{2}\right)^{\beta_{k}}}, \sqrt{1-\prod_{k=1}^{q+1}\left(1-\left(\mu_{\epsilon_{k}}^{b}\right)^{2}\right)^{\beta_{k}}}\right],\left[\prod_{k=1}^{q+1}\left(v_{\epsilon_{k}}^{a}\right)^{\beta_{k}}, \prod_{k=1}^{q+1}\left(v_{\epsilon_{k}}^{b}\right)^{\beta_{k}}\right]\right)
\end{aligned}
$$




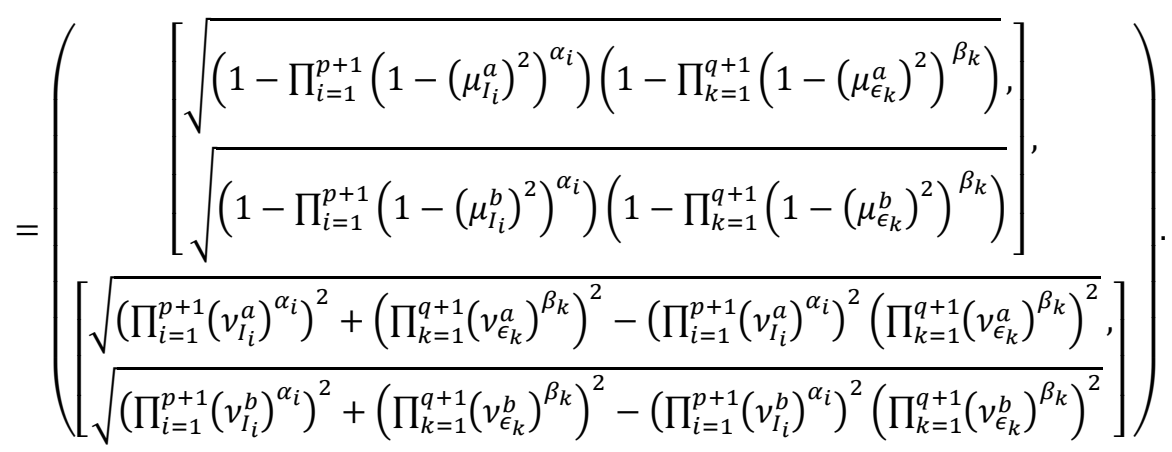

Persamaan 13 benar untuk setiap $n$ dan $l$. Sehingga terbukti bahwa Persamaan 13 berlaku.

3.2 Multi Criteria Decision Making menggunakan operator group generalized interval value Pythagorean fuzzy

Misal diberikan jenis mobil $A_{i}$ untuk $i=1,2, \cdots, n$ dengan kriteria penilaian $C_{j}$ untuk $j=$ $1,2, \cdots, m$. Setiap kriteria $C_{j}$ memiliki pembobot masing-masing yang menentukan prioritas kriteria yang diinginkan oleh pelanggan. Informasi fuzzy jenis mobil berdasarkan kriteria tertentu dinotasikan sebagai $A_{i j}$. Pelanggan meminta saran pada pengamat ahli dalam bidang otomotif yang dinotasikan dengan $\epsilon_{k}$ untuk $k=1,2, \cdots, l$ dalam pengambilan keputusan. Pelanggan memberikan pembobot untuk setiap pengamat ahli $\epsilon_{k}$ sebagai bentuk prioritas kepercayaan pelanggan pada masing-masing pengamat ahli. Hasil penilaian pengamat ahli dalam bidang otomotif pada setiap mobil $A_{i}$ adalah GGP $\epsilon_{k i}$. Informasi fuzzy $A_{i j}$ dan GGP $\epsilon_{k i}$ dinyatakan dalam IVPFN. Selanjutnya, dua koleksi IVPFN tersebut akan diagregasi menggunakan operator GGIVPFWA dan GGIVPFWG untuk memilih suatu mobil. Proses pemilihan mobil yang akan dibeli oleh pelanggan menggunakan operator GGIVPFWA dan GGIVPFWG adalah:

1. Menentukan beberapa pilihan jenis mobil, yaitu $A_{i}$ untuk $i=1,2, \cdots, n$ dengan kriteria $C_{j}$ untuk $j=1,2, \cdots, m$ serta pembobot $\alpha_{j}$ dengan $\alpha_{j} \in[0,1]$ dan $\sum_{j=1}^{m} \alpha_{j}=1$.

2. Menyatakan informasi fuzzy jenis mobil $A_{i}$ berdasarkan kriteria $C_{j}$ dalam bentuk IVPFN $A_{i j}=\left(\left[\mu_{A_{i j}}^{a}, \mu_{A_{i j}}^{b}\right],\left[v_{A_{i j}}^{a}, v_{A_{i j}}^{b}\right]\right)$.

3. Menentukan penasihat pengambil keputusan $\epsilon_{k}$ untuk $k=1,2, \cdots, l$ serta pembobotnya, yaitu $\beta_{k}$ dengan $\beta_{k} \in[0,1]$ dan $\sum_{k=1}^{l} \beta_{j}=1$.

4. Menyatakan penilaian $\epsilon_{k}$ atas setiap mobil $A_{i}$ sebagai GGP dalam bentuk IVPFN $\epsilon_{k i}=$ $\left(\left[\mu_{\epsilon_{k i}}^{a}, \mu_{\epsilon_{k i}}^{b}\right],\left[v_{\epsilon_{k i}}^{a}, v_{\epsilon_{k i}}^{b}\right]\right)$.

5. Mengagregasi informasi fuzzy jenis mobil $A_{i j}$ dan GGP $\epsilon_{k i}$ menggunakan operator agregasi GGIVPFWA dan GGIVPFWG.

6. Menghitung nilai score dari GGIVPFWA dan GGIVPFWG. 
7. Mengurutkan alternatif terbaik yang dapat dipilih berdasarkan nilai score. Semaking tinggi nilai score, semakin tinggi pula urutan pilihan alternatif tersebut.

Misalkan seorang pelanggan ingin membeli sebuah mobil dari beberapa jenis mobil. Misalkan terdapat lima pilihan jenis mobil, yaitu $A_{1}, A_{2}, A_{3}, A_{4}$, dan $A_{5}$. Pelanggan memiliki empat kriteria untuk memilih suatu mobil, yaitu $C_{1}=$ harga mobil, $C_{2}=$ model mobil, $C_{3}=$ desain mobil, dan $C_{4}=$ warna mobil. Pembobot kriteria yang diberikan oleh Pelanggan adalah $\alpha=$ $(0.15,0.20,0.35,0.30)$. Informasi kriteria yang diberikan oleh Pelanggan untuk setiap mobil dinyatakan dalam IVPFN $A_{i}=\left(\left[\mu_{A_{i}}^{a}, \mu_{A_{i}}^{b}\right],\left[v_{A_{i}}^{a}, v_{A_{i}}^{b}\right]\right)$ dan disajikan dalam tabel berikut.

Tabel 1. Informasi Fuzzy Jenis Mobil

\begin{tabular}{c|cccc}
\hline & $\boldsymbol{C}_{\mathbf{1}}$ & $\boldsymbol{C}_{\mathbf{2}}$ & $\boldsymbol{C}_{\mathbf{3}}$ & $\boldsymbol{C}_{\mathbf{4}}$ \\
\hline $\boldsymbol{A}_{\mathbf{1}}$ & $([0.48,0.67],[0.15,0.44])$ & $([0.40,0.62],[0.10,0.33])$ & $([0.40,0.45],[0.30,0.32])$ & $([0.30,0.42],[0.20,0.23])$ \\
$\boldsymbol{A}_{\mathbf{2}}$ & $([0.50,0.71],[0.18,0.21])$ & $([0.50,0.72],[0.18,0.44])$ & $([0.50,0.61],[0.20,0.27])$ & $([0.60,0.72],[0.30,0.40])$ \\
$\boldsymbol{A}_{\mathbf{3}}$ & $([0.50,0.63],[0.30,0.43])$ & $([0.45,0.57],[0.25,0.35])$ & $([0.63,0.68],[0.40,0.50])$ & $([0.30,0.55],[0.10,0.25])$ \\
$\boldsymbol{A}_{\mathbf{4}}$ & $([0.46,0.59],[0.25,0.46])$ & $([0.45,0.50],[0.20,0.29])$ & $([0.35,0.55],[0.05,0.34])$ & $([0.50,0.62],[0.40,0.47])$ \\
$\boldsymbol{A}_{\mathbf{5}}$ & $([0.30,0.46],[0.25,0.28])$ & $([0.35,0.43],[0.13,0.15])$ & $([0.30,0.51],[0.05,0.27])$ & $([0.30,0.44],[0.10,0.24])$
\end{tabular}

Pelanggan meminta saran pada tiga pengamat ahli bidang otomotif, yaitu $\epsilon_{1}, \epsilon_{2}, \epsilon_{3}$ dengan pembobot $\beta=(0.25,0.45,0.30)$. Informasi penilaian yang diberikan oleh pengamat ahli disebut sebagai GGP dan dinyatakan dalam IVPFN $\epsilon_{k i}=\left(\left[\mu_{\epsilon_{k i}}^{a}, \mu_{\epsilon_{k i}}^{b}\right],\left[v_{\epsilon_{k i}}^{a}, v_{\epsilon_{k i}}^{b}\right]\right)$ untuk $k=1,2,3$ dan $i=1,2,3,4,5$. Informasi GGP dari $A_{i}$ yang diberikan oleh pengamat ahli adalah

Tabel 2. Group Generalized Parameter

\begin{tabular}{c|ccc}
\hline & $\boldsymbol{C}_{\mathbf{1}}$ & $\boldsymbol{C}_{2}$ & $\boldsymbol{C}_{3}$ \\
\hline $\boldsymbol{A}_{\mathbf{1}}$ & $([0.40,0.90],[0.28,0.30])$ & $([0.30,0.70],[0.18,0,20])$ & $([0.30,0.70],[0.05,0.10])$ \\
$\boldsymbol{A}_{\mathbf{2}}$ & $([0.30,0.70],[0.15,0.20])$ & $([0.20,0.80],[0.05,0.10])$ & $([0.50,0.80],[0.20,0.50])$ \\
$\boldsymbol{A}_{\mathbf{3}}$ & $([0.30,0.80],[0.05,0.10])$ & $([0.40,0.80],[0.10,0.30])$ & $([0.50,0.90],[0.15,0.40])$ \\
$\boldsymbol{A}_{\mathbf{4}}$ & $([0.20,0.80],[0.15,0.20])$ & $([0.20,0,70],[0.10,0.20])$ & $([0.20,0.80],[0.05,0.20])$ \\
$\boldsymbol{A}_{\mathbf{5}}$ & $([0.45,0.60],[0.25,0.40])$ & $([0.40,0.60],[0.20,0.30])$ & $([0.40,0.70],[0.15,0.30])$
\end{tabular}

Informasi pada Tabel 1 dan 2 selanjutnya diagregasi menggunakan operator GGIVPFWA dan GGIVPFWG dan memberikan hasil sebagai berikut.

Tabel 3. Nilai Agregasi GGIVPFWA dan GGIVPFWG untuk $A_{i}$

\begin{tabular}{c|cc}
\hline & $\boldsymbol{\Phi}\left(\boldsymbol{A}_{\boldsymbol{i}}\right)$ & $\boldsymbol{\Psi}\left(\boldsymbol{A}_{\boldsymbol{i}}\right)$ \\
\hline $\boldsymbol{A}_{\mathbf{1}}$ & $([0.1276,0.4079],[0.2345,0.3505])$ & $([0.1216,0.3719],[0.2881,0.3783])$ \\
$\boldsymbol{A}_{\mathbf{2}}$ & $([0.1852,0.5338],[0.2385,0.3706])$ & $([0.1539,0.5246],[0: 2656,0.4530])$ \\
$\boldsymbol{A}_{3}$ & $([0.2090,0.5175],[0.2479,0.4359])$ & $([0.1813,0.5047],[0.3129,0.4897])$
\end{tabular}




\begin{tabular}{c|cc}
\hline & $\boldsymbol{\Phi}\left(\boldsymbol{A}_{\boldsymbol{i}}\right)$ & $\boldsymbol{\Psi}\left(\boldsymbol{A}_{\boldsymbol{i}}\right)$ \\
\hline $\boldsymbol{A}_{\mathbf{4}}$ & $([0.0876,0.4339],[0.1801,0.4225])$ & $([0.0854,0.4259],[0.2806,0.4370])$ \\
$\boldsymbol{A}_{\mathbf{5}}$ & $([0.1285,0.2964],[0.2152,0.3906])$ & $([0.1275,0.2918],[0.2380,0.4011])$
\end{tabular}

Langkah selanjutnya adalah menghitung nilai score $S\left(\Phi\left(A_{i}\right)\right)$ dan $S\left(\Psi\left(A_{i}\right)\right)$ menggunakan Persamaan (2). Nilai score $S\left(\Phi\left(A_{i}\right)\right)$ dan $S\left(\Psi\left(A_{i}\right)\right)$ disajikan dalam tabel berikut.

Tabel 4. Nilai Score GGIVPFWA dan GGIVPFWG untuk $A_{i}$

\begin{tabular}{l|cc}
\hline & $\mathbf{S}\left(\boldsymbol{\Phi}\left(\boldsymbol{A}_{\boldsymbol{i}}\right)\right)$ & $\boldsymbol{S}\left(\boldsymbol{\Psi}\left(\boldsymbol{A}_{\boldsymbol{i}}\right)\right)$ \\
\hline $\boldsymbol{A}_{\mathbf{1}}$ & 0.0024 & -0.0365 \\
$\boldsymbol{A}_{2}$ & 0.0625 & 0.0116 \\
$\boldsymbol{A}_{3}$ & 0.0300 & -0.0251 \\
$\boldsymbol{A}_{\mathbf{4}}$ & -0.0075 & -0.0405 \\
$\boldsymbol{A}_{\mathbf{5}}$ & -0.0472 & -0.0581
\end{tabular}

Berdasarkan Tabel 4, urutan alternatif terbaik dari jenis mobil $A_{i}$ untuk $i=1,2,3,4,5$ menggunakan operator GGIVPFWA adalah $A_{2}>A_{3}>A_{1}>A_{4}>A_{5}$. Hasil yang sama juga diberikan oleh operator GGIVPFWG. Hal ini menunjukkan bahwa penggunaan GGP pada Tabel 2 untuk mengakurasi informasi fuzzy pada Tabel 1 efektif. Hasil yang diberikan mungkin berbeda jika hanya GP tertentu yang digunakan untuk mengakurasi informasi fuzzy. Berikut adalah perbandingan urutan alternatif dari setiap operator menggunakan GP tertentu dengan pembobot $\beta_{1}=0.55$ dan $\beta_{2}=0.45$ untuk mengagregasi informasi fuzzy dengan dua GP.

Tabel 5. Perbandingan Hasil Operator Agregasi menggunakan GP tertentu

\begin{tabular}{c|c}
\hline Operator Agregasi & Hasil \\
\hline GIVPFWA1 $_{1}$ & $A_{3}>A_{2}>A_{4}>A_{1}>A_{5}$ \\
GIVPFWG $_{1}$ & $A_{2}>A_{3}>A_{4}>A_{1}>A_{5}$ \\
\hline GIVPFWA2 $_{2}$ & $A_{2}>A_{3}>A_{4}>A_{1}>A_{5}$ \\
GIVPFWG $_{2}$ & $A_{2}>A_{3}>A_{1}>A_{4}>A_{5}$ \\
\hline GIVPFWA3 $_{3}>A_{1}>A_{2}>A_{5}>A_{3}$ \\
GIVPFWG $_{3}$ & $A_{4}>A_{1}>A_{4}>A_{3}>A_{5}>A_{2}$ \\
\hline GGIVPFWA1,2 $_{1,2}$ & $A_{1}>A_{3}>A_{4}>A_{1}>A_{5}$ \\
GGIVPFWG $_{1,2}$ & $A_{2}>A_{3}>A_{1}>A_{4}>A_{5}$ \\
\hline GGIVPFWA $_{1,3}$ & $A_{3}>A_{2}>A_{1}>A_{4}>A_{5}$ \\
GGIVPFWG $_{1,3}$ & $A_{2}>A_{3}>A_{4}>A_{1}>A_{5}$ \\
\hline GGIVPFWA $_{2,3}$ & $A_{2}>A_{3}>A_{1}>A_{4}>A_{5}$ \\
GGIVPFWG ${ }_{2,3}$ & $A_{2}>A_{1}>A_{3}>A_{4}>A_{5}$ \\
\hline \hline
\end{tabular}


Langkah selanjutnya untuk mengambil keputusan dalam kasus MCDM adalah memverifikasi hasil keputusan yang diberikan oleh operator GGIVPFWA dan GGIVPFWG menggunakan weighted similarity maeasure. Berdasarkan Persamaan (8), nilai interval value Pythagorean fuzzy ideal solution $A^{*}$ adalah

$$
A^{*}=\left\{\begin{array}{l}
([0.30,0.46],[0.25,0.28]),([0.35,0.43],[0.13,0.15]), \\
([0.63,0.68],[0.40,0.50]),([0.60,0.72],[0.30,0.40])
\end{array}\right\}
$$

Diberikan $\delta=0.55$ dan $\gamma=0.45$. Berdasarkan Persamaan (7), nilai weighted similarity measure dari jenis mobil $A_{i}$ untuk $i=1,2,3,4,5$ dengan ideal solution $A^{*}$ adalah

Tabel 6. Weighted Similarity Measure antara $A_{i}$ dengan $A^{*}$

\begin{tabular}{c|c}
\hline & $\mathbf{S M}^{*}\left(\boldsymbol{A}_{\boldsymbol{i}}, \boldsymbol{A}^{*}\right)$ \\
\hline $\boldsymbol{A}_{\mathbf{1}}$ & $([0.5168,0.9408])$ \\
$\boldsymbol{A}_{\mathbf{2}}$ & $([0.6016,0.9729])$ \\
$\boldsymbol{A}_{\mathbf{3}}$ & $([0.5864,0.9664])$ \\
$\boldsymbol{A}_{\mathbf{4}}$ & $([0.5116,0.9381])$ \\
$\boldsymbol{A}_{\mathbf{5}}$ & $([0.4848,0.9322])$
\end{tabular}

Berdasarkan Tabel 6, diperoleh urutan alternatif menggunakan weighted similarity measure adalah $A_{2}>A_{3}>A_{1}>A_{4}>A_{5}$. Hasil tersebut sama dengan hasil menggunakan operator GGIVPFWA dan GGIVPFWG. Hal ini menunjukkan bahwa operator GGIVPFWA dan GGIVPFWG dapat menyelesaikan kasus MCDM secara efektif dan akurat.

Urutan alternatif dari operator agregasi pada Tabel 5 menunjukkan bahwa hanya terdapat satu operator yang menghasilkan keputusan yang sama dengan weighted similarity measure, yaitu operator GIVPFWG 2 , GGIVPFWG 1,2 , dan GGIVPFWA 2,3 . Hal ini menunjukkan bahwa penggunaan GP tertentu memberikan dampak langsung pada hasil keputusan. Jika GP yang digunakan salah, maka keputusan yang dihasilkan operator agregasi kemungkinan besar salah. Sehingga, kesalahan yang diakibatkan oleh GP tertentu dapat diatasi dengan menggunakan GGP.

Berdasarkan uraian diatas, keputusan yang dihasilkan adalah mobil $A_{2}$ merupakan pilihan terbaik yang dapat dibeli Pelanggan sesuai dengan kriteria $C_{j}$ untuk $j=1,2,3,4$. Hal tersebut ditunjukkan dengan weighted similarity measure yang menghasilkan mobil $A_{2}$ dengan nilai tertinggi. Sebaliknya, mobil $A_{5}$ adalah mobil yang jauh dari kriteria yang diinginkan Pelanggan dibandingkan jenis mobil lainnya. Hal tersebut ditunjukkan dengan weighted similarity measure yang menghasilkan mobil $A_{5}$ dengan nilai terendah. 


\section{Simpulan}

Berdasarkan uraian pembahasan diatas, dapat disimpulkan bahwa operator agregasi GGIVPFWA dibangun dari dua konsep, yaitu konsep GGP dan IVPFWA. Sedangkan operator agregasi GGIVPFWG dibangun dari konsep GGP dan IVPFWG. Aplikasi operator agregasi GGIVPFWA dan GGIVPFWG dalam kasus MCDM menghasilkan keputusan yang efektif dan akurat.

\section{Daftar Pustaka}

[1] L. A. Zadeh, "Fuzzy sets," Inf. Control, vol. 8, no. 3, pp. 338-353, Jun. 1965, doi: 10.1016/S0019-9958(65)90241-X.

[2] K. T. Atanassov, "Intuitionistic fuzzy sets," Fuzzy Sets Syst., vol. 20, no. 1, pp. 87-96, 1986, doi: 10.1016/S0165-0114(86)80034-3.

[3] K. Atanassov and G. Gargov, "Interval valued intuitionistic fuzzy sets," Fuzzy Sets Syst., vol. 31, no. 3, pp. 343-349, 1989, doi: 10.1016/0165-0114(89)90205-4.

[4] R. R. Yager and A. M. Abbasov, "Pythagorean membership grades, complex numbers, and decision making," Int. J. Intell. Syst., vol. 28, no. 5, pp. 436-452, May 2013, doi: $10.1002 /$ int.21584.

[5] X. Peng and Y. Yang, "Some Results for Pythagorean Fuzzy Sets," Int. J. Intell. Syst., vol. 30, no. 11, pp. 1133-1160, Nov. 2015, doi: 10.1002/int.21738.

[6] M. Agarwal, K. K. Biswas, and M. Hanmandlu, "Generalized intuitionistic fuzzy soft sets with applications in decision-making," Appl. Soft Comput. J., vol. 13, no. 8, pp. 35523566, 2013, doi: 10.1016/j.asoc.2013.03.015.

[7] H. Garg, “A New Generalized Pythagorean Fuzzy Information Aggregation Using Einstein Operations and Its Application to Decision Making," Int. J. Intell. Syst., vol. 31, no. 9, pp. 886-920, Sep. 2016, doi: 10.1002/int.21809.

[8] H. Garg, "Generalized Pythagorean Fuzzy Geometric Aggregation Operators Using Einstein t-Norm and t-Conorm for Multicriteria Decision-Making Process," Int. J. Intell. Syst., vol. 32, no. 6, pp. 597-630, Jun. 2017, doi: 10.1002/int.21860.

[9] K. Rahman, S. Abdullah, M. Shakeel, M. S. Ali Khan, and M. Ullah, "Interval-valued Pythagorean fuzzy geometric aggregation operators and their application to group decision making problem," Cogent Math., vol. 4, no. 1, p. 1338638, 2017, doi: $10.1080 / 23311835.2017 .1338638$. 
[10] K. Rahman, A. Ali, and M. S. A. Khan, "Some Interval-Valued Pythagorean Fuzzy Weighted Averaging Aggregation Operators and Their Application to Multiple Attribute Decision Making,” Punjab Univ. J. Math., vol. 50, no. 2, pp. 113-129, 2018.

[11] J. Feng, Q. Zhang, and J. Hu, “Group Generalized Pythagorean Fuzzy Aggregation Operators and Their Application in Decision Making," IEEE Access, vol. 8, pp. 138004138020, 2020, doi: 10.1109/ACCESS.2020.3010718.

[12] Q. Zhang, J. Hu, J. Feng, A. Liu, and Y. Li, "New Similarity Measures of Pythagorean Fuzzy Sets and Their Applications," IEEE Access, vol. 7, pp. 138192-138202, 2019, doi: 10.1109/ACCESS.2019.2942766.

[13] H. Li, Y. Cao, L. Su, and Q. Xia, “An interval pythagorean fuzzy multi-criteria decision making method based on similarity measures and connection numbers," Inf., vol. 10, no. 2, pp. 1-18, 2019, doi: 10.3390/info10020080.

[14] R. E. Moore, Methods and Applications of Interval Analysis. Society for Industrial and Applied Mathematics, 1979.

[15] X. Peng and Y. Yang, "Fundamental Properties of Interval-Valued Pythagorean Fuzzy Aggregation Operators," Int. J. Intell. Syst., vol. 31, no. 5, pp. 444-487, May 2016, doi: 10.1002/int.21790. 